\title{
EDITORIAL
}

\section{EuCAP 2016 special issue}

\author{
ANJA SKRIVERVIK, CARLO RIVA AND LARS FOGED, EUCAP 2016 TPC CHAIRS
}

This special issue of the International Journal of Microwave and Wireless Technlogy presents an expanded version of several selected contributions to the 2016 edition of the European Conference on Antennas and Propagation (EuCAP).

EuCAP is organized by the European Association on Antennas and Propagation (EurAAP), which was created in the frame of the European Network of Excellence "ACE Antenna Centre of Excellence" (visit www.euraap.org), as the point of reference of the European Antenna and Propagation scientific community.

The European Conference on Antennas and Propagation provides a wide forum for Antennas and Propagation experts (typically about 1200 attendees) from academia, industry, research institutes, agencies, and providers with high quality exchanges and presentations covering all development aspects and including measurements. Expected benefits are intensified collaborations in Europe and beyond. The conference includes an exhibit to display the state-of-the-art on technology, instrumentation, test facilities, software tools, and documentation available in the field of the conference. The latter cover all the classical emerging domains in Antenna, Propagation and Measurement techniques for Antennas and Electromagnetic Waves.

The $10^{\text {th }}$ Issue of EUCAP was held from the $10^{\text {th }}$ to the $15^{\text {th }}$ of April in Davos, Switzerland, and was attended by 1176 delegates. The conference included 1060 papers presented in oral, convened or poster sessions, several workshops and short courses. Moreover, three keynote and 12 invites speakers presented the latest trends and innovations in the fields of Antennas, Propagation and Measurement. As usual, all papers presented had passed a rigorous peer review process. The latter was organized by the 39 members of the TPC, distribution the load over the 400 members of the review panels.

This special issue comprises a selection of papers that were highly ranked by the EuCAP reviewers and covering topics of interest for the microwave community. Their authors were invited to prepare an expanded version of their paper, which then underwent the classic review process of the International Journal of Microwave and Wireless Technology. As associated editors for this special issue, we would like to thank first the authors for having accepted the invitation, the reviewers whose comments have contributed to the quality of the final papers, and the editorial team of the Journal whose daily management of the review process was of great help to the associate editors of this issue. We hope that you will enjoy reading this issue, intended as a bridge between the Antenna and propagation community on one side and the microwave community on the other.

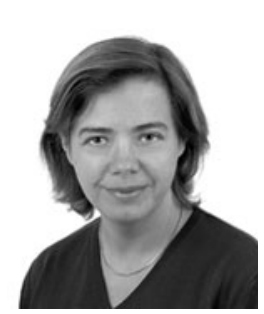

Anja Skrivervik obtained her electrical engineering degree from Ecole Polytechnique Fédérale de Lausanne in 1986, and her PhD from the same institution in 1992, for which she received the Latsis award. After a stay at the University of Rennes as an invited Research Fellow and two years in the industry, she returned part time to EPFL as an Assistant Professor in 1996, and is now a Professeur Titulaire at this institution, where she is the head of the Mocrowave nad Antenna Group. Her teaching activities include courses on microwaves and antennas. Her research activities include electrically small antennas, implantable and wearable antennas, multifrequency and ultra wideband antennas, and numerical techniques for electromagnetics. She is author or co-author of more than 200 peer reviewed scientific publications.

She is very active in European collaboration and European projects. She was the chairperson of the Swiss URSI until 2012, is a Board member of the European School on Antennas and is frequently requested to review research programs and centers in Europe. She is a board member and scretary/treasurer of the European Association on Antennas and Propagation (EurAAP).

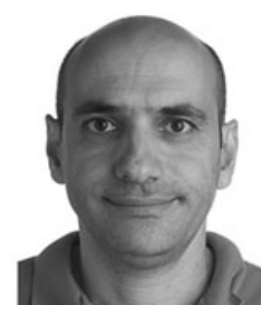

Carlo G. Riva was born in $1965 . \mathrm{He}$ received the Laurea Degree in Electronic Engineering and the $\mathrm{PhD}$ degree in Electronic and Communication Engineering, from Politecnico di Milano, Milano, Italy, in 1990 and 1995, respectively. In 1999, he joined the Dipartimento di Elettronica, Informazione e Bioingegneria, Politecnico di Milano, where, since 2006, he has been an Associate Professor of electromagnetic fields. He participated in the Olympus, Italsat and (the running) Alphasat Aldo Paraboni (for this experiment he has been appointed Principal Investigator by ASI in 2012) propagation measurement campaigns, in the COST255, COST280 and COSTICo802 international projects on propagation and telecommunications and in the Satellite Communications Network of Excellence (SatNEx). He is Chairman of WP 3 J of ITU-R SG 3 ('Propagation fundamentals') and Associate Editor of IEEE Transactions on Antennas and Propagation. He is the author of about 200 papers published in international journals or international conference proceedings. His main research activities are in the fields of 
atmospheric propagation of millimeter-waves through the atmosphere (measurements and modelling), Fade Mitigation Techniques, and satellite communication adaptive systems.

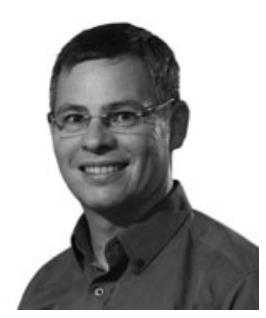

Lars Jacob Foged was born in Viborg, Denmark in 1966. He received his B.Sc from Aarhus Teknikum, Denmark in 1988 and M.Sc. in Electrical Engineering from California Institute of Technology, USA in 1990.

He became a "graduate trainee" of the European Space Agency, ESTEC in the Netherlands and in the following ten years, designed communication and navigation antennas in the satellite industry. He led the antenna design effort on the recently launched GALILEO space segment and performed the multi-physics design of shaped reflectors for the EUTELSAT W satellites, still serving European users. Following his passion to rationalize the multi-disciplinary antenna design process, including measurements and simulations, he joined MVG (formerly SATIMO) in 2001 and founded the Italian branch office.

In MVG, he initiated close collaborations with universities and research institutions with focus on antennas for single and multi-probe measurements and techniques for analysis/postprocessing. He has held different technical leadership positions in MVG and is currently the Scientific Director of the Microwave Vision Group, and Associate Director of Microwave Vision Italy.
He contributed to the European network of excellence ACE as an Activity Leader on "Antenna Measurements and Facility sharing" from 2004 to 2008 . He became a member of the EURAAP Delegate Assembly and responsible for the Working Group on Antenna Measurements from 2009 to 2012. He was Vice-Chair of the EUCAP conference in 2011, Industrial Chair of EUCAP conferences in 2012, 2014, 2017, and Technical Program Chair of EUCAP in 2016. In 2015, he contributed to the foundation of the AMTA Italian node.

Since 2006, He has been a member of the board of the European School of Antennas (ESOA), and technical responsible and teacher in Antenna Measurement courses in Europe and Asia. He became Secretary of the IEEE Antenna Standards Committee in 2004 and has contributed to the development of different standards on antennas and measurements. $\mathrm{He}$ is involved in the evolution of the IEC 62209 Standard(s) on Human Exposure to Electromagnetic Fields since 2010. In 2016, he accepted to lead the Industry Initiatives Committee (IIC), a standing committee of IEEE APS with the purpose to improve industrial participation in IEEE activities

He is a Senior Member of IEEE and an occasional reviewer on the IEEE Transactions and Letters. $\mathrm{He}$ is an Edmond S. Gillespie Fellow of AMTA and received the Distinguished Achievement Award from AMTA in 2017. He has authored or co-authored more than 200 journal and conference papers on antenna design and measurement topics and received the "Best Technical Paper Award" from AMTA in 2013. He has contributed to five books and standards, and holds four patents. 